\title{
Borehole Seismic and Strain Observatories in Seafloor Settings-Experiences after ODP Legs 186, 191, 195 and Future Plans
}

\author{
by Eiichiro Araki and Kiyoshi Suyehiro
}

\section{Borehole Seismo-Geodetic Observatories}

In the period of Ocean Drilling Program Legs 186, 191, and 195, we successfully deployed a set of seismo-geodetic sensors in deep seafloor boreholes in four locations (JT1, JT2, WP1, and WP2). The JT1 and JT2 borehole observatories are located in the landward slope of the Japan Trench, where we expect seismic activity beneath the observatories. These borehole observatories gave us good platforms to look at the dynamic process on the plate boundary in the seafloor.

The WP1 and WP2 are considered a part of a global seismic network of observatories currently distributed mostly on land and ocean islands. For permanent seismic observation in the seafloor setting, installation of broadband seismic sensors in the seafloor borehole was recommended, and candidate locations were chosen (Suyehiro et al., 2006). The WP1 and WP2 sites are one of the first borehole observatories to implement such a permanent seafloor observatory.

We called these seafloor borehole observatories "NEREID" ('Neath Seafloor Equipment for Recording Earth's Internal Deformation). The NEREID observatories are characterized by several key features that are thought to acquire optimum performance from the borehole sensors.
Firstly, sensors are cemented at the bottom of the borehole. This is very important because long-period seismic and tilt/ strain sensors are sensitive to fluid flow around them, so it is necessary to couple them to the ground very well. Cementing sensors at the bottom of the borehole was able to fix sensors rigidly in place, and eliminated fluid around the sensors. Cementing is necessary especially for strainmeters, because the strain of the ground should be transmitted to the sensing cylinder of the strainmeter by some means. On land, it has been widely practiced for that purpose.

Secondly, separate cables connect borehole sensors uphole for power feeding and seafloor data recording. This is to deal with possible failure of the sensors, cables, and connectors in the borehole during and after the installation in the borehole. It worked very well, and we were able to replace failed sensors after the installation without affecting operation of other sensors.

Sensors deployed in these observatories were configured to target specifications needs in each location of the observatories. For JT1 and JT2 observatories, a tiltmeter (AG510), a strainmeter (dilatometer and three component types), and broadband seismometers (CMG1T, PMD) are chosen to mainly target the earthquakes and slow deformation processes below the observatory. The WP1 and WP2 observatories are important for monitoring global seismic activity, so two identical broadband seismometers (Guralp CMG1T) were installed for redundancy.

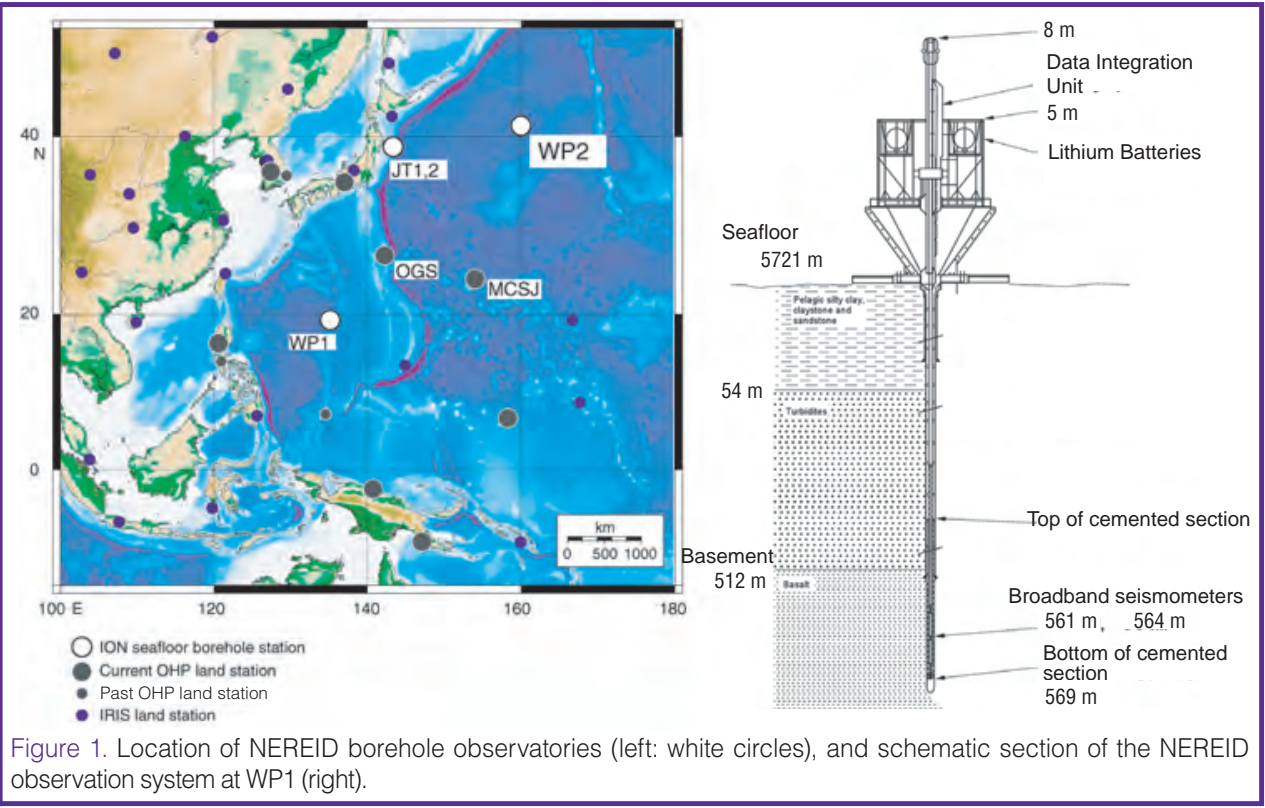

Data from borehole sensors are recorded in the seafloor. Electric power necessary for these sensors is provided by a stack of seawater batteries or lithium batteries stored in a titanium sphere. Data are recovered by $\mathrm{ROV}$ by retrieving the data recorder because the amount of the recorded seismic data was as large as $10 \mathrm{~GB}$ per year.

We conducted visits to each observatory for data recovery and maintenance once a year or more. From most of the observatories, 


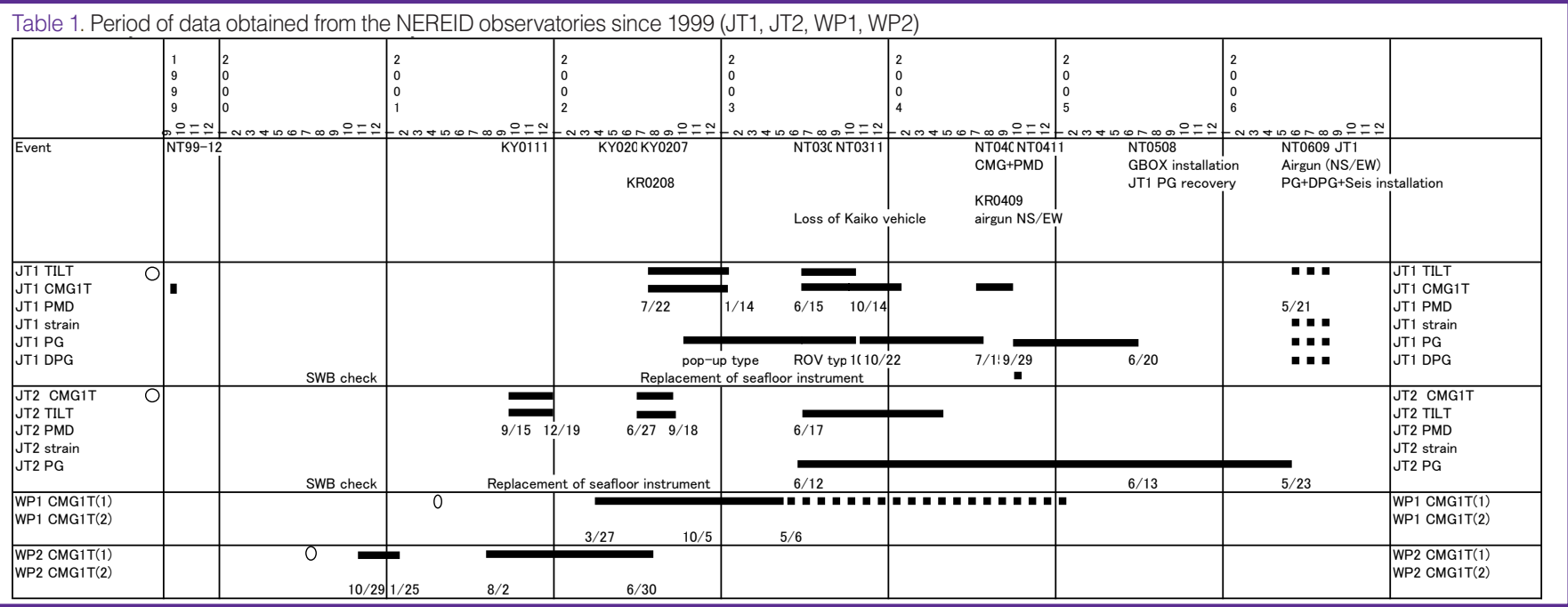

data for more than a year were recovered so far (Table 1 ). The observatories are still functional more than 5 years postinstallation.

\section{Improvement of Seismic and Tilt Measurement}

The seismic data from the NEREID borehole observatories exhibited excellent performance with low background noise. The JT1 borehole seismometer showed less horizontal noise than a seismometer in the seafloor by $80 \mathrm{~dB}$ (Araki et al., 2004) in a 1000-second period. As a result, we were able to see effects of long period ocean gravity waves tilting the ground (at JT1 borehole $1.2 \mathrm{~km}$ below seafloor). This environment in the borehole enabled us to detect smaller teleseismic events (Shinohara et al., 2006), resulting in better understanding of seismic structure in the deep solid earth, such as structure of the transition zone of the Earth's mantle (Suetsugu et al., 2005).

Effects of earth tide were also seen in the seismic records from JT1, JT2, and WP2 boreholes. The observed tidal effect can be explained by deformation of ground due to tidal force on the solid earth. Broadband seismometers in the seafloor also show tidal effects, but this is usually the effect from tidal motion of water on the seafloor.

Furthermore, up to a year period, we investigated the stability of boreholes from tilt records. JT2 borehole tilt drifted at approximately 7 microradians per year. JT1 borehole showed a similar drift rate. JT1 and JT2 boreholes are located at a seismogenic plate boundary with different background seismicity. We sought slow events in the tilt record, as well as local earthquakes, to evaluate the activity of subducting plate boundary. No slow event was identified during the initial observation period in these boreholes.

Borehole seismometers are also very useful for observing local seismic activity. Figure 2 compares a small local earthquake's records from JT1 NEREID borehole observatory and nearby seafloor OBSs (Ocean Bottom Seismographs). The OBS records exhibit monotonic response around $10 \mathrm{~Hz}$ especially in the horizontal component. This prevents precise analysis of the hypocenter and mechanism of earthquakes. Borehole records do not show such a response for all components; therefore, installing seismometers in boreholes will be very important for the study of dynamic processes of earthquakes beneath the seafloor.

\section{Future Plans}

We continue observations in existing long-term observatories. Activities in these borehole observatories include not only data recovery but also renovation of seafloor equipment to allow very long-term (more than several years) continuous observations by tiltmeter.

On the basis of present experiences of seismo-geodetic observation in the existing ODP seafloor boreholes, we plan on future long-term borehole observation in the IODP era. We proposed to implement scientific long-term borehole observatories in the Nankai Trough south of Japan as a part of NanTroSEIZE project. The area where Nankai Trough drilling is conducted covers a whole subduction process of oceanic plate, before the subduction to seismo-genesis of mega-thrust earthquake of magnitude greater than 8 .

The plan of Nankai Trough borehole observatory includes CORKs (see Becker and Davis, 2005) and a long-term obser-

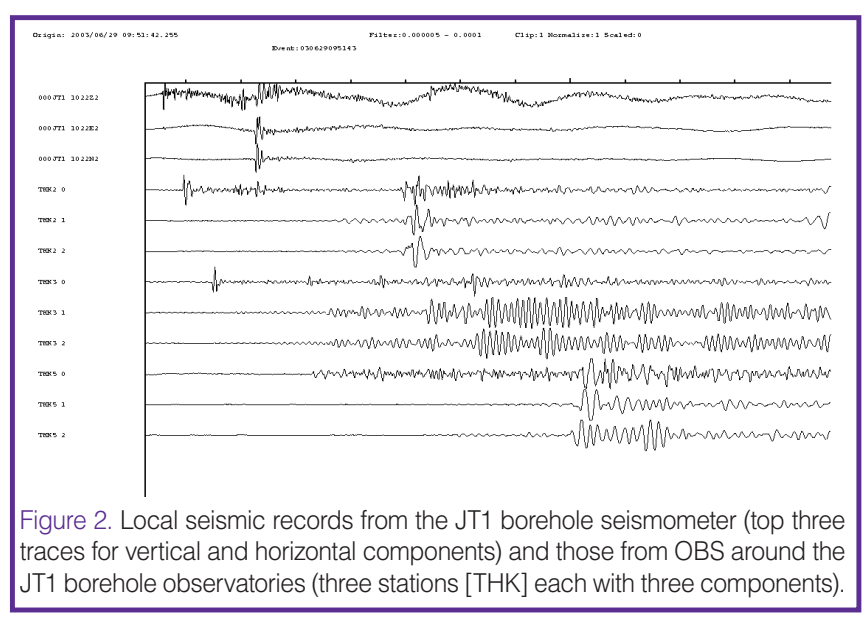




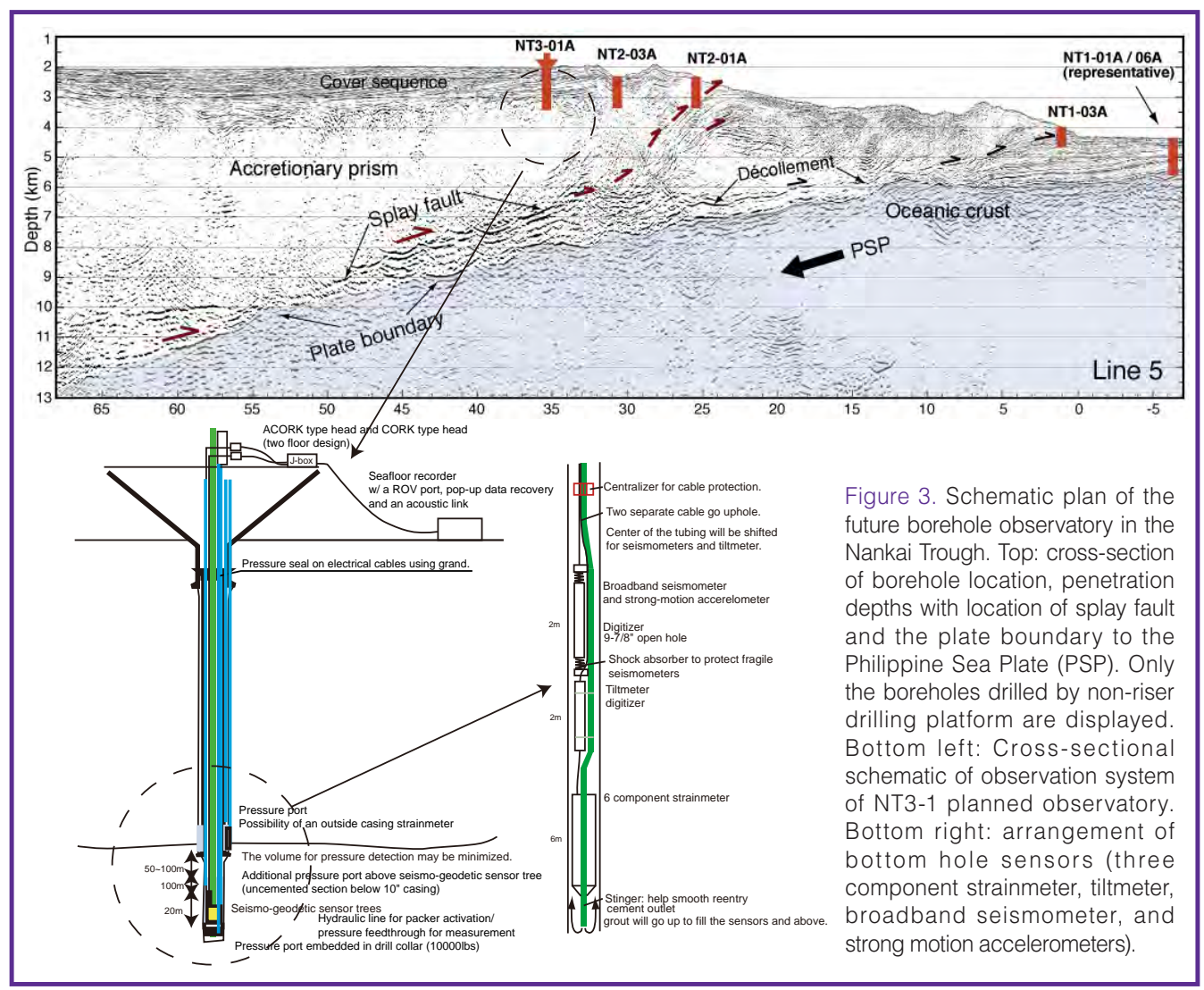

vatory in a deep borehole of $3.5 \mathrm{~km}$ below the seafloor that requires a riser drilling platform. In addition to these observatories, we also plan to establish a seismo-geodetic-hydrological observatory that integrates the present A-CORK system for hydrological measurement and NEREID system for seismo-geodetic measurement. Figure 3 shows a schematic diagram of the observation system. At the bottom of the borehole drilled by a non-riser platform, we plan to install a three-component strainmeter, a tiltmeter, a strong motion accelerometer, and a broadband seismometer. We will also install a hydraulic tube below the seismic sensors to measure pore-pressure. By integrating various observation parameters obtained from the borehole observatory, we expect to obtain a better understanding of dynamics in the plate boundary of the Nankai Trough.

Understanding the seismogenesis of mega-thrust earthquakes, which is one of the major targets of the Nankai Trough drilling project (NanTroSEIZE), cannot be achieved solely by activities during drilling. Continuous long-term observations in these borehole observatories should play a key role in documenting and understanding ongoing subduction processes. Sufficient infrastructures and sciencetechnology commitment are required to realize continuous long-term observations to achieve scientific goals. JAMSTEC will establish a scientific seismic network (DONET) around the area of the Nankai Trough drilling by 2010. The network utilizes submarine fiber optic cable to feed power and transmit data from instruments installed in the seafloor. We also plan to connect the borehole observatories to the DONET submarine cable network to assure long-term realtime observations using the IODP boreholes.

\section{References}

Araki, E., Shinohara, M., Sacks, S., Linde, A., Kanazawa, T., Shiobara, H., Mikada, H., and Suyehiro, K., 2004. Improvement of seismic observation in the ocean by use of seafloor boreholes. Bull. Seismol. Soc. Am., 94:(2)678-690, doi: 10.1785/0120020088.

Becker, K. and Davis, E.E., 2005. A review of CORK designs and operations during the Ocean Drilling Program. In Fisher, A.T., Urabe, T., Klaus, A., and the Expedition 301 Scientists (Eds.) Proceedings of the Integrated Ocean Drilling Program, Volume 301, College Station, Texas (Integrated Ocean Drilling Program Management International, Inc.), 104, d o i : $10.2204 /$ i o d p . proc.301.104.2005.

Shinohara, M., Araki, E., Kanazawa, T., Suyehiro, K., Mochizuki, M., Yamada, T., Nakahigashi, K., Kaiho, Y., and Fukao, Y., 2006. Deep-sea borehole seismological observatories in the Western Pacific: temporal variation of seismic noise level and event detection. Ann. Geophys., 49(2/3):625-641.

Suetsugu, D., Shinohara, M., Araki, E., Kanazawa, T., Suyehiro, K., Yamada, T., Nakahigashi, K., Shiobara, H., Sugioka, H., Kawai, K., and Fukao, Y., 2005. Mantle discontinuity depths beneath the West Philippine Basin from receiver function analysis of deep-sea borehole and seafloor broadband waveforms. Bull. Seismol. Soc. Am., 95(5):1947-1956.

Suyehiro, K., Montagner, J.-P., Stephen, R.A., Araki, E., Kanazawa, T., Orcutt, J., Romanowicz, B., Sacks, S., and Shinohara, M., 2006. Ocean seismic observatories. Oceanogr., 19(4):144149.

\section{Authors}

Eiichiro Araki, Japan Agency for Marine-Earth Science and Technology (JAMSTEC), 2-15 Natsushima-cho, Yokosuka, 237-0061, Japan, e-mail: araki@jamstec.go.jp.

Kiyoshi Suyehiro, Japan Agency for Marine-Earth Science and Technology (JAMSTEC), 2-15 Natsushima-cho, Yokosuka, 237-0061, Japan. 